\title{
Distribution patterns in the benthic diversity of the eastern English Channel
}

\author{
A. Foveau ${ }^{1,4, *}$, N. Desroy ${ }^{1}$, J. C. Dauvin ${ }^{2}$, J. M. Dewarumez ${ }^{3}$ \\ ${ }^{1}$ IFREMER, Laboratoire Environnement-Ressources Finistère - Bretagne Nord, CRESCO, 38 rue du Port Blanc \\ BP 70 134, 35801 Dinard Cedex, France \\ ${ }^{2}$ Université de Caen Basse-Normandie, Laboratoire Morphodynamique Continentale et Côtière, CNRS, UMR M2C 6143, \\ 24, rue des Tilleuls, 14000 Caen, France \\ ${ }^{3}$ Université Lille Nord de France, Station Marine de Wimereux, UMR CNRS 8187 LOG, 28, Avenue Foch, BP 80, \\ 62930 Wimereux, France \\ ${ }^{4}$ Present address: GEMEL, Station d'études en baie de Somme de l'Université de Picardie Jules Verne, \\ 115 quai Jeanne d'Arc, 80230 Saint-Valery-sur-Somme, France
}

\begin{abstract}
Understanding the distribution of specific diversity is currently an important focus in marine research, and the role of marine biodiversity has been fully recognised as essential for the proper functioning of the biosphere. The objective of this study was to explain the distribution of macrobenthic taxonomic richness (vagile epifauna, endofauna and sessile epifauna) in the eastern part of the English Channel using both classical methods and applying the mid-domain effect (MDE) model. High diversity was encountered in the eastern English Channel (875 taxa), with high-diversity areas often comprising gravelly or pebbly sediments. Sessile epifauna represented $25 \%$ of this inventory, revealing the importance of this group. Our results underline the existence of randomness in the observed species richness distribution due to large number of species with restricted ranges.
\end{abstract}

KEY WORDS: Benthic community distribution - Species richness gradient · Mid-domain effect · Chao index Resale or republication not permitted without written consent of the publisher

\section{INTRODUCTION}

The role of marine biodiversity has only recently been fully recognised as essential for the proper functioning of the biosphere (Worm et al. 2006). In community ecology, understanding the spatial distribution of specific diversity has become an important research focus. In situ, the species taxonomic level is the most easily approachable study unit. Specific diversity is evaluated by estimators of the number of species (species richness) and other indices, such as Shannon's diversity or Pielou's equitability index, derived from information theory. However, these estimators more or less reduce biodiversity to the number of species, ignoring that certain functions provided by ecosystems, and often involved in their resilience, can result from interactions among species (Elmqvist et al. 2003).

Less is known about marine biodiversity than about terrestrial ecosystems (Hendriks et al. 2006), since the challenges faced in the marine environment in terms of size and inaccessibility make it considerably more difficult to conduct studies. However, it is essential that marine biodiversity should be documented to enhance our understanding of temporal and spatial ecosystem functions within specific regions of the world. This would ultimately lead to an integrated approach focusing on entire ecosystems rather than fragments of systems.

Since the work of Sanders (1968), biologists, ecologists and biogeographers have tried to understand how benthic species diversity is distributed with 
respect to large-scale gradients such as depth (Willig et al. 2003). Relationships between latitudinal changes and biodiversity do not necessarily need to follow linear or even monotonic functions to be useful (Rex et al. 1993, Thrush et al. 2006), and emergent patterns are often driven by the interaction of processes operating at different scales. To understand the role of broad-scale processes in biodiversity, it is necessary to integrate responses operating at different scales of space and time (Thrush et al. 2006). Following these ideas, Ellingsen (2001) and Ellingsen \& Gray (2002) conducted studies along the Norwegian continental shelf and showed that patterns of diversity within a region may depend on the spatial scale over which they are measured, and that differences can occur among habitats considered uniform. In many of their analyses conducted over large areas (considered benthoscapes as defined by Zajac 2008), correlations among various measures of diversity and environmental variables were not strong. The unexplained part of variation may lie in how populations and communities and the diversity patterns generated are shaped by the benthoscape structure. The importance of habitat characteristics in structuring soft sediment diversity was reinforced by Hewitt et al. (2005), who showed that small-scale biogenic structures and habitat-forming deposits (such as shell debris) can significantly affect $\beta$-diversity. Another biogeographic theory, the mid-domain effect (MDE), was developed in the mid-1990s by Colwell \& Hurtt (1994) and was based on (and sensitive to) the distribution range of a given species (extremes of a range boundary and midpoint within a bounded domain). The MDE is considered a null model, i.e. excluding all environmental, biological and historical processes. Under most conditions, this model, which runs random combinations of geographical ranges within a defined bounded domain, produces a unimodal curve with a mid-domain peak (Colwell 2008). This model has been confirmed in spatialised applications in 1 (Willig \& Lyons 1998, Colwell \& Lees 2000) and 2 dimensions (Bokma et al. 2001). Reviews and critiques of this model can be found in Zapata et al. (2005), Hawkins et al. (2005) and Colwell et al. (2004).

The objective of the present paper is to explain the distribution of macrobenthic taxonomic richness (vagile epifauna, endofauna and sessile epifauna) in the eastern part of the English Channel using both classical methods and the MDE. Data used were collected during surveys that aimed to update the knowledge on benthic fauna in the eastern part of the English Channel acquired 30 yr ago in historical surveys, and to provide a quantitative description of benthic communities and data usable in trophic foodweb studies or ecosystem approaches.

\section{MATERIALS AND METHODS}

\section{Study site}

From 2004 to 2007, a total of 461 stations were sampled from the RV 'Côtes de la Manche', in the eastern basin of the English Channel and the South Bight of the North Sea, between $49^{\circ} 30^{\prime} 00^{\prime \prime}$ and $51^{\circ} 18^{\prime} 00^{\prime \prime} \mathrm{N}$ latitude and $1^{\circ} 00^{\prime} 00^{\prime \prime} \mathrm{W}$ and $2^{\circ} 30^{\prime} 01^{\prime \prime} \mathrm{E}$ longitude.

In the eastern English Channel, tidal current strengths increase from 1.5 to 3 knots from the south to the northeast as the narrower part of the Dover Strait is approached. Flow velocity decreases in the southern North Sea where it does not exceed 2 knots (SHOM 1968). Variations in the speed of the tidal current create a sedimentary gradient (Larsonneur et al. 1982); pebbles and gravels dominate in the open sea, whereas coastal areas are dominated by large homogeneous sand banks and associated channel systems (Fig. 1).

The water quality of the sampling area is largely influenced by 2 main estuaries: the Seine estuary in the south-west and the Scheldt delta in the north-east. Depending on the direction, intensity and duration of the wind, the plumes of both rivers can reach the Dover Strait zone and modify water salinity up to 2 to 3 nautical miles off the French coast (Brylinski et al. 1988). Other smaller rivers (i.e. Somme, Authie, Canche, Liane, Aa and Yser, Fig. 1) and runoff from sea cliffs contribute to a decrease in the salinity of coastal waters. Although the outflows from these sources are relatively low, they may be locally significant at low tide.

\section{Field sampling design}

Sampling was carried out during 6 surveys conducted between March 2004 and August 2007. The sampling grid was regular (resolution of 5 ' in latitude and longitude, Fig. 2) with areas more intensely sampled in the framework of local scientific programmes (e.g. Flanders sandbanks, south Dover Strait sandbanks, Ridens of Boulogne; Fig. 1). Sampling was quantitative or qualitative, depending on the sediment encountered. On soft sediments, quantitative samples were collected with a Hamon grab. Three replicates 


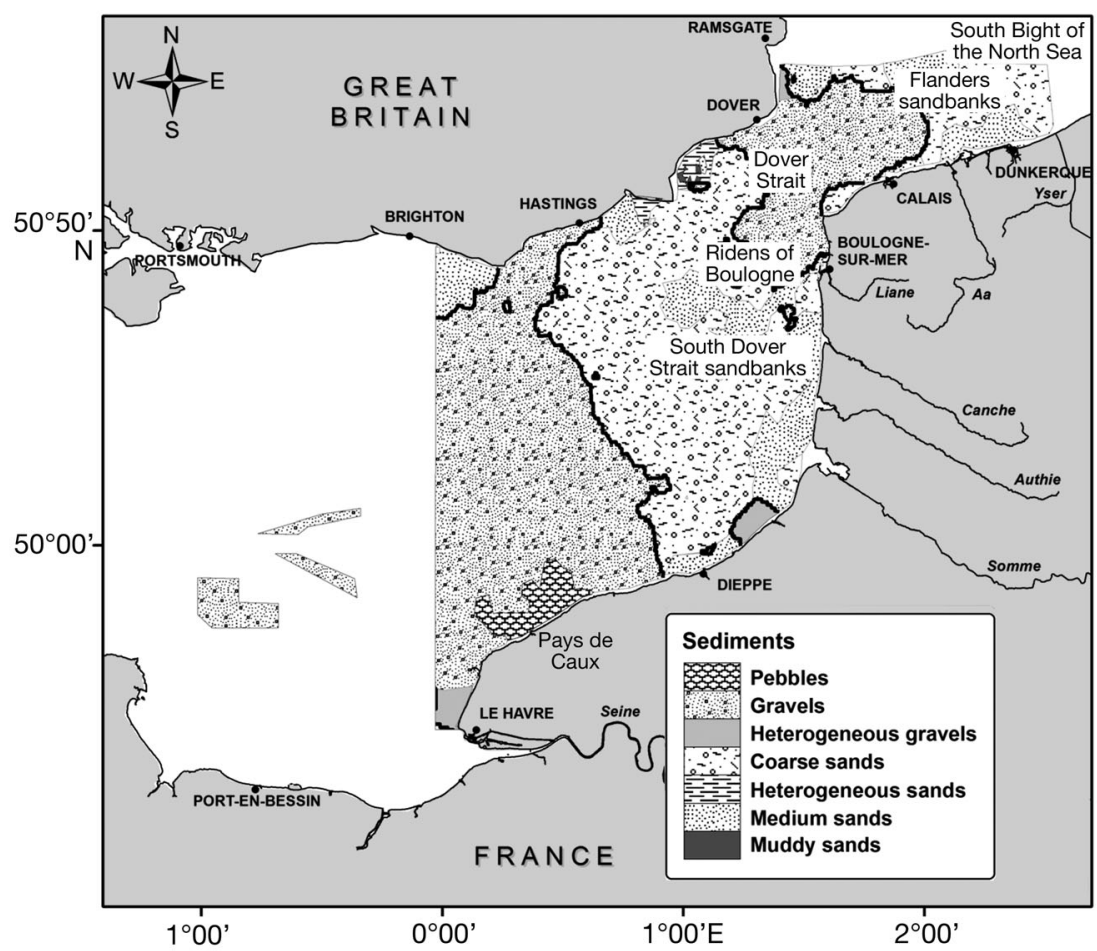

Fig. 1. Sediment categories in the eastern English Channel (adapted from Folk 1954 in Foveau 2009). Thick black lines show the boundaries between gravel/ pebble and sand sediments

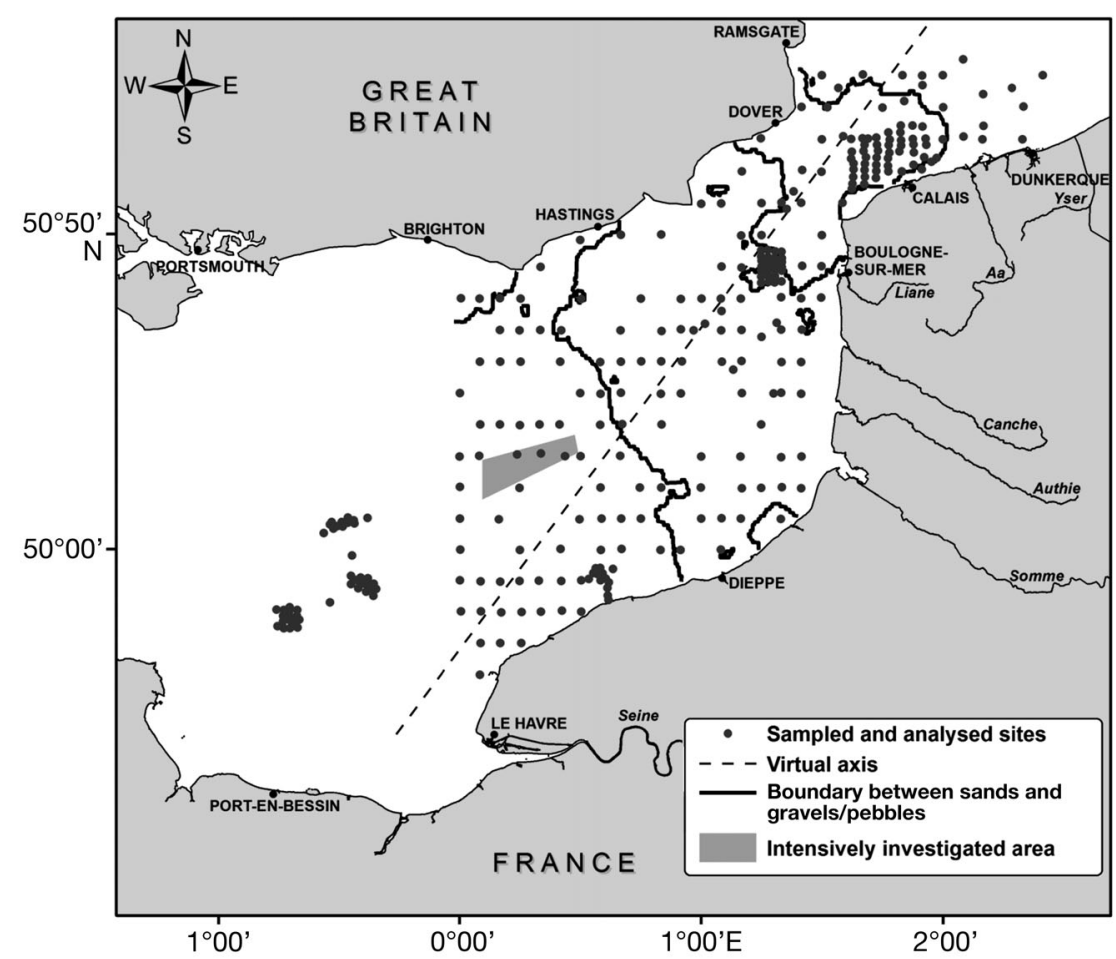

Fig. 2. Location of samples taken in the eastern English Channel (grey dots: sites of the principal grid sampled and analysed; grey area: intensively investigated site (high station density), exact positions of stations cannot be provided), dashed line: virtual axis; thick black lines: boundaries between gravel/pebble and sand sediments $\left(0.25 \mathrm{~m}^{2}\right)$ were taken at each station, the first for granulometric analysis, and the other 2 for benthic fauna analysis (species and biomass determinations). In the presence of hard substrates (gravels, pebbles and cobbles), a Rallier du Baty dredge was used (sampling standardised to 30 1). Sieving was performed onboard using 2 mesh sizes: a circular $2 \mathrm{~mm}$ mesh (which does not retain juveniles but collects more than $95 \%$ of the macrobenthic biomass, see Ghertsos 2002) and a circular $1 \mathrm{~mm}$ mesh. The retained material was preserved for analysis in 5\% buffered formaldehyde. A visual description of the sediment type was recorded, along with the depth of the water column, and the location and times at which the sample was collected (replicates were collected from within a close range of each site, using the Differential Global Positioning System).

Sediment samples were analysed for grain size distribution (wet sieving). The macrofauna, including sessile epifauna (countable and non-countable taxa), were identified to the lowest possible taxon and enumerated when possible. The biomass of each taxon was determined based on $g$ of ash-free dry weight per $0.5 \mathrm{~m}^{2}$ (loss of weight of dry organisms after $6 \mathrm{~h}$ at $520^{\circ} \mathrm{C}$ ) as recommended by the ICES Benthos Ecology Working Group (BEWG 1986). As far as possible, photographs of sediment and species were taken, and a specimen of each species was conserved to create a photo database and a reference collection.

\section{Analysis of sedimentary and biological data}

Of the 461 stations sampled, samples from 318 stations (sieved on $2 \mathrm{~mm}$ mesh) were retained for analysis (Fig. 2). In order to account for substrate heterogeneity, the number of stations studied was increased in heterogeneous areas and reduced in homogeneous ones. 
Table 1. Sediment type equivalents among classifications: groups used in present study, modified Folk (1954) classification (in Foveau 2009) and Folk (1954) classification

\begin{tabular}{|c|c|c|}
\hline Group in present study & Modified Folk classification & Folk classification \\
\hline \multirow[t]{5}{*}{ Gravel/pebbles } & Pebbles & Gravels $(\mathrm{G}):>80 \%$ is $>2 \mathrm{~mm}$ and $>50 \%$ is $>20 \mathrm{~mm}$ \\
\hline & Gravels & Other gravels $(\mathrm{G}):>80 \%$ is $>2 \mathrm{~mm}$ and $<50 \%$ is $>20 \mathrm{~mm}$ \\
\hline & & Sandy gravels (sG): $30-80 \%$ is $>2 \mathrm{~mm}$ and sand:mud ratio is $>9: 1$ \\
\hline & Heterogeneous gravels & Muddy sandy gravels (msG) \\
\hline & & Gravelly muddy sands (gmS) \\
\hline \multirow{6}{*}{ Sand } & Coarse sands & Gravelly sands (gS) \\
\hline & & Slightly gravelly sands ((g)S) \\
\hline & Medium sands & Sands (S) \\
\hline & Muddy sands & Muddy sands (mS) \\
\hline & Heterogeneous sands & Slightly gravelly muddy sands ((g)mS) \\
\hline & & Slightly gravelly sandy muds ((g)sM) \\
\hline
\end{tabular}

A modified Folk classification (Folk 1954, Foveau 2009), based on 7 categories of sediment types (Table 1), was used to determine the sedimentary type for each station. Sediments were categorised in this study into coarse sediments (gravels/pebbles) and fine particles (sand; see Fig. 1 for locations of these sediments in the studied area).

Although an evaluation of several diversity indices was undertaken (Foveau 2009), only results for total taxa are presented here. The taxonomic richness for all taxa (countable and non-countable) was mapped, using the kriging interpolation method and Genstat software (@ VSN International), and represented via ArcGIS software (@ ESRI).

PRIMER software was also used to realise the species accumulation curve. Because it is the most pertinent for analysing presence/absence data including epifauna, we used the Chao2 (Chao 1984) estimator and compared it to the accumulation curve of the number of taxa observed. The non-parametric Chao2 method is based on species occurrence. It rests on the hypothesis that non-observed taxa are rare species, and considers that a species is rare when the taxon occurs at only 2 stations.

Changes in the taxonomic richness were studied along a virtual south-west/north-east axis (Fig. 2). All stations were represented according to their geographic coordinates expressed in a Lambert II geodesic system, and a regression line (with the best $\mathrm{R}^{2}$ ) was drawn between these points $(y=0.7288 x+2252)$. All stations were projected on this axis, and new coordinates (in Lambert II, which allows translation in $\mathrm{km}$ ) were assigned to stations and associated to values of taxonomic richness. To visualise how taxonomic richness changes along the eastern English Channel, the virtual axis was divided either by fixing the number of sampled stations (constant sampling effort, 32 stations) or by defining a number of equidistant sections (for ex- ample, sections of $22.43 \mathrm{~km}$ if the virtual axis of $224.3 \mathrm{~km}$ was divided into 10 sections). For each configuration, the number of species was counted per division and represented as histograms. Along this transect, numbers of taxa were also reported for each sampling station, and an accumulation curve was built from these projections (for all stations, but also for the 2 categories of sediment i.e. sand and gravel/pebbles). The observed taxonomic richness distribution was compared to the MDE null model, created using the RangeModel 5.0 software (Colwell 2006), which produces a randomisation disposition of the observed range sizes within the defined studied area (continuous model, Box 5 in Colwell \& Lees 2000). The generation of observed species distribution and predicted mean pattern of richness across the domain was used to represent the $95 \%$ confidence intervals, for 100 randomisations of range placement, as suggested by Colwell (2008). The mean displacement $(D)$ between the simulated and the average random curves was calculated with the program developed by Veech (2000).

\section{RESULTS}

\section{General characteristics of taxonomic richness and links to superficial sediment cover}

In total, we identified 875 taxa. Fauna consisted of 251 annelid taxa (28.7\% of the fauna), 234 arthropod taxa $(26.7 \%), 159$ mollusc taxa $(18.2 \%), 72$ bryozoan taxa $(8.2 \%)$ and 55 cnidarian taxa $(6.3 \%)$ for the main phyla (Table 2). Unique taxa (present at only 1 site) and taxa present at 2 sites represented 21.6 and $10.4 \%$, respectively. About $13.8 \%$ of the taxa were recorded at $\geq 50$ sites, but no taxon was present throughout the entire study area (the most frequently represented taxon occurred at 223 stations). 
Table 2. Total number of taxa found in this study compared to results of previous studies; percentage values in parentheses. Sources - 1: Rees et al. (1999) for the English part of the North Sea, English Channel and Celtic Sea; 2: Rees et al. (2007) for the North Sea; 3: Kröncke et al. (2011) for the central and southern North Sea; 4: Hily et al. (2008) for the Bay of Biscay; 5: Dauvin \& Dewarumez (2002) for Roscoff; 6: Dauvin \& Dewarumez (2002) for Wimereux; 7: European Register of Marine Species (W. Appeltans pers. comm.). Gaps indicate that data were not analyzed. RT: taxonomic richness

\begin{tabular}{|c|c|c|c|c|c|c|c|c|}
\hline & \multirow{2}{*}{ Present study } & \multicolumn{7}{|c|}{ - Previous studies } \\
\hline & & 1 & 2 & 3 & 4 & 5 & 6 & 7 \\
\hline Total RT & 875 & 430 & 1500 & 455 & 163 & 1856 & 769 & 20927 \\
\hline Annelida & $253(28.9)$ & $186(43.3)$ & & & $76(47.0)$ & $429(23.1)$ & $160(20.8)$ & $2271(10.9)$ \\
\hline Arthropoda & $237(27.1)$ & $112(26.0)$ & & & $37(23.0)$ & $251(13.5)$ & $148(19.2)$ & $6703(32.0)$ \\
\hline Mollusca & $159(18.2)$ & $76(17.7)$ & & & $29(18.0)$ & $421(22.7)$ & $161(20.9)$ & $3861(18.4)$ \\
\hline Bryozoa & $72(8.2)$ & & & & & $142(7.7)$ & 64 (8.3) & $802(3.8)$ \\
\hline Cnidaria & $55(6.3)$ & & & & & 213 (11.5) & 91 (11.8) & $1266(6.0)$ \\
\hline Porifera & $31(3.5)$ & & & & & $200(10.8)$ & $52(6.8)$ & $1472(7.0)$ \\
\hline Echinodermata & $23(2.6)$ & $19(4.4)$ & & & $14(9.0)$ & $45(2.4)$ & $20(2.6)$ & $659(3.1)$ \\
\hline Chordata & $15(1.7)$ & & & & & $62(3.3)$ & $31(4.0)$ & $402(1.9)$ \\
\hline Others & $30(3.5)$ & $37(8.6)$ & & & & $93(5.0)$ & $42(5.5)$ & $3491(16.7)$ \\
\hline
\end{tabular}

Most of the stations associated with sand (muddy to coarse sands, heterogeneous or not) had a taxonomic richness less than 80 (Fig. 3, grey bars). On gravel/ pebbles (heterogeneous or not), taxonomic richness per station was higher, ranging from 60 to 150 (Fig. 3, black line). Some exceptions were observed in boundary areas, where the assignment of sediment type was problematic (especially for the gravel/ coarse sand proportions).

The absolute value estimated by the Chao2 index (1071.1 \pm 37.6 taxa) was higher than the observed value (Fig. 4). The absence of an asymptote on the estimated taxonomic richness curve suggested that the value was underestimated.

\section{Spatial distribution of taxonomic richness in the eastern English Channel}

Total taxonomic richness reached a maximum in the central part of the Channel, off the 'Pays de Caux' and in the Dover Strait (Fig. 5). The lowest values were observed on the sandbanks located south of the Dover Strait and in the South Bight of the North Sea (Fig. 5). Uncountable taxa, belonging to the sessile epifauna, were logically mainly associated with pebbled areas, located in the 'Pays de Caux' and the Dover Strait (Fig. 6). The location of diversity hotspots (total or sessile epifauna only) coincided with the distribution of gravel and pebbles (Figs. 5 \& 6).

Regardless of the partition type considered (fixed number of stations or equidistant sections), taxonomic richness varied along the virtual axis following a bimodal distribution (Fig. 7). The highest values of taxonomic richness (>400 taxa) were observed in the first

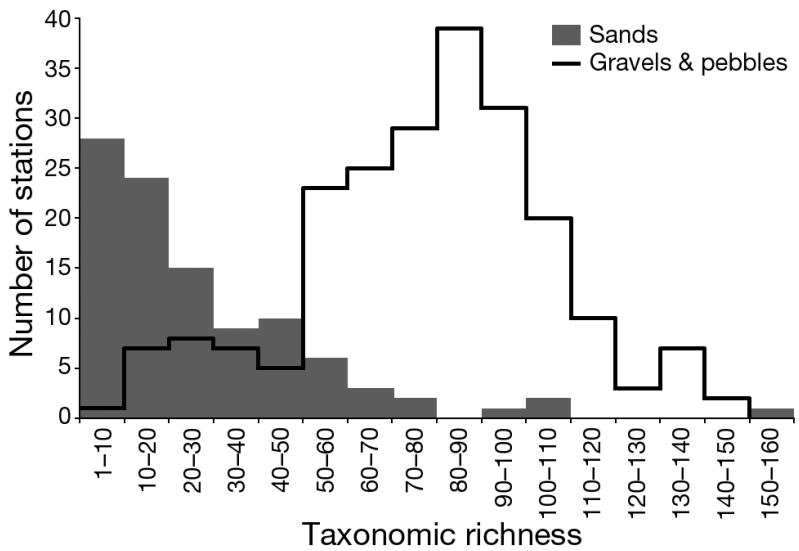

Fig. 3. Number of sampled stations plotted against observed taxonomic richness, divided into the 2 sediment groups, sands and gravels/pebbles

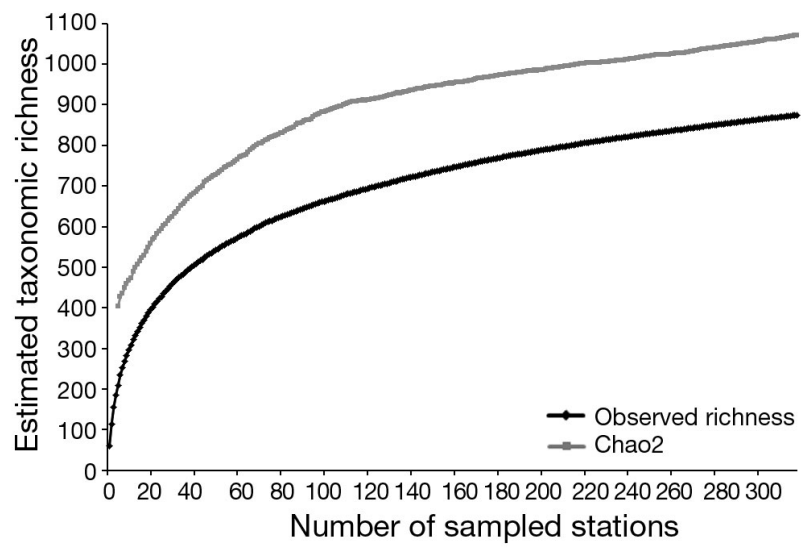

Fig. 4. Species accumulation curve obtained from the Chao2 estimator and for the observed taxonomic richness 


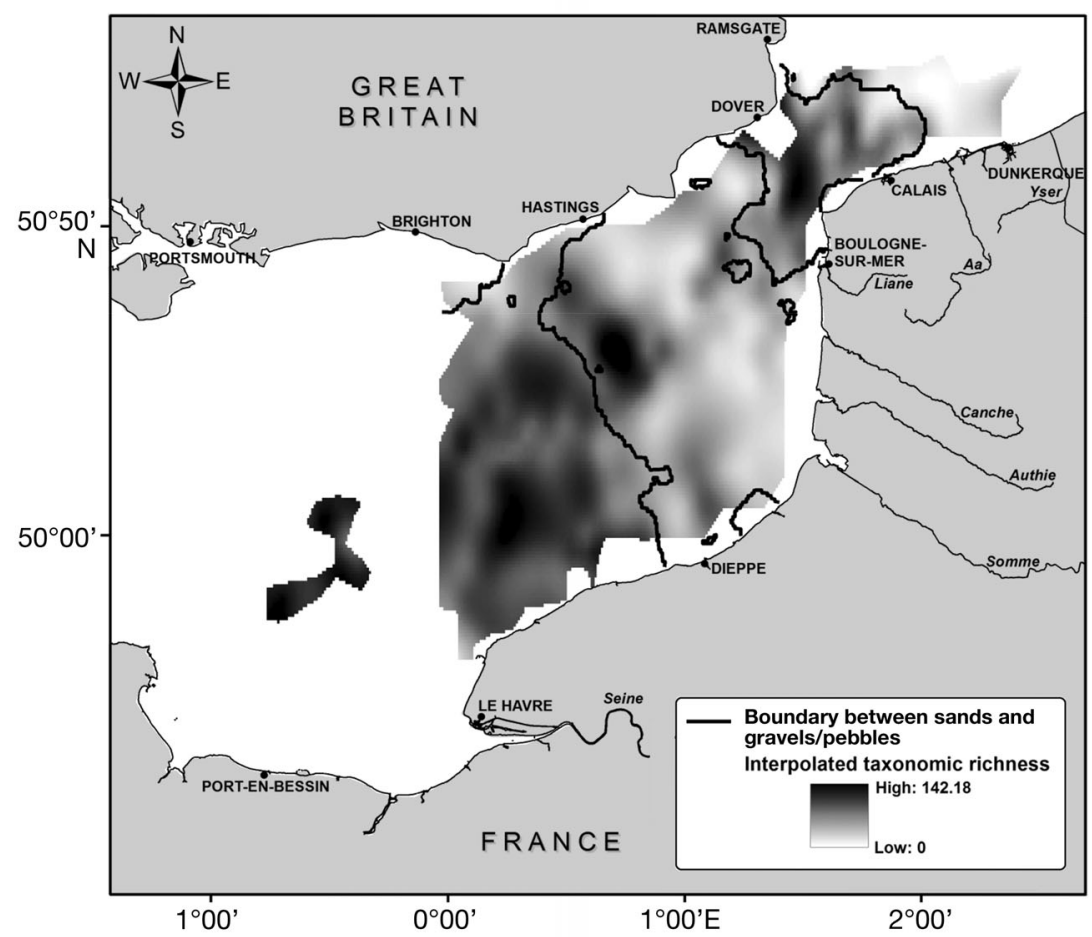

Fig. 5. Distribution of the total taxonomic richness in the eastern part of the English Channel

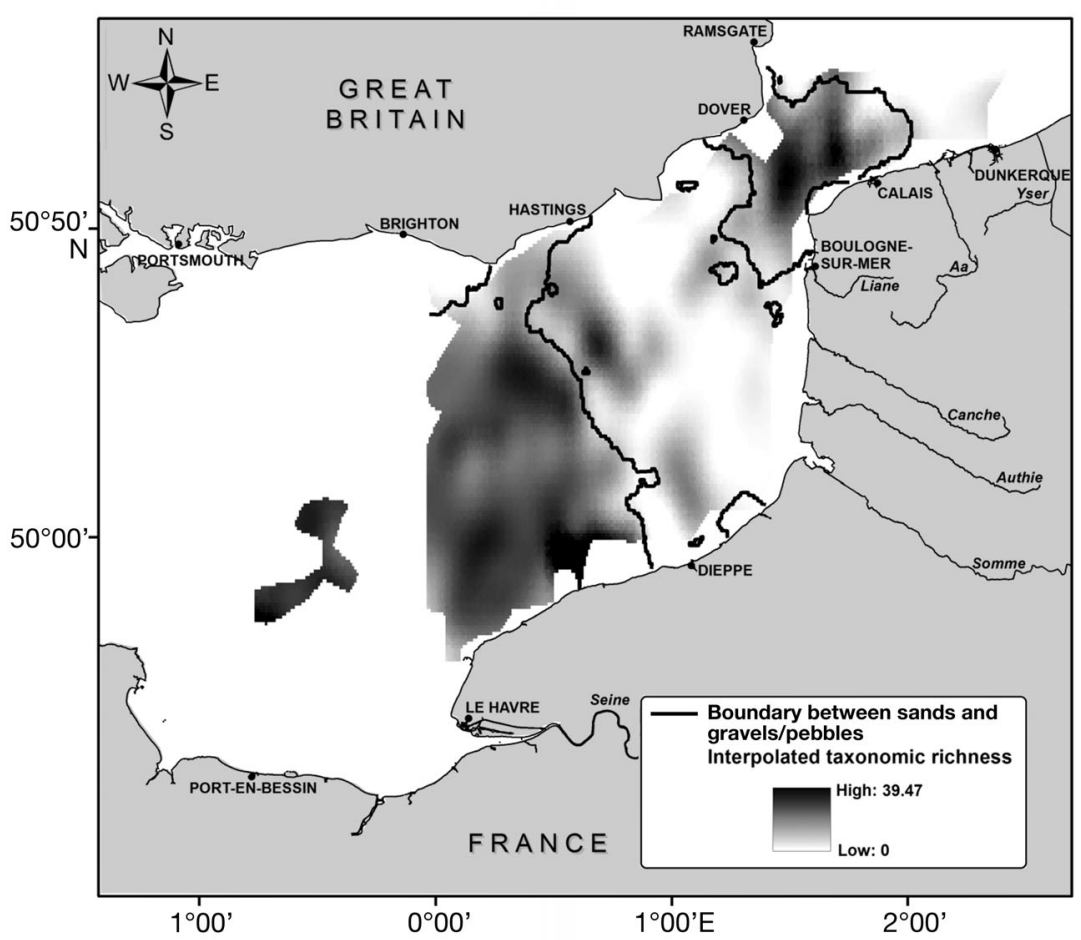

Fig. 6. Distribution of the taxonomic richness of sessile epifauna in the eastern part of the English Channel and third sections, i.e. in the gravel/ pebbles area, and in the Dover Strait area respectively (>300 taxa). The lowest values were observed in the area where sand dominated. The same approach, when carried out on the sand and gravel/pebble categories separately, confirmed the stronger contribution of gravel/pebbles to taxonomic richness. For sand, 2 peaks were observed, corresponding to the large sandbank areas (south Dover Strait sandbanks and Flanders sandbanks), and raising the overall level of taxonomic richness (grey areas in Fig. 7).

When the virtual axis was divided into sections of $1 \mathrm{~km}$ length, the sum of the number of species recorded followed a bell-shaped curve (Fig. 8A) with a maximum of 502 taxa in the middle of the area studied. The absence of an inflexion point in the cumulative curve could mean that the turnover of taxa (i.e. replacement of one taxon by another) in this area was constant. The same methodology was applied for each sediment type (Fig. 8B,C). While a nearly centred bell-shaped curve is observed for gravel/pebble sediments, the curve characterising sand sediments is asymmetrical. However, these 3 cumulative curves follow a similar pattern.

Compared to the curve computed with RangeModel, our observed taxonomic richness curve exhibits higher values in the western and central parts of the gradient (Fig. 9). Results from Veech's displacement test give an observed value, $D_{\text {obs }}$ at 256.29 with a range of predicted values, $D_{\text {pred, be- }}$ tween 2.17 and 22.06 and a probability of $<0.0001$ that $D_{\text {obs }} \leq \max D_{\text {pred }}$ (based on 1000 trials). The taxonomic richness curve is highly significant: $D_{\text {obs }}$ is high (256.29), and no null iterations (out of 1000) had a higher $D$ value or a higher p-value than the observed value. According to Veech (2000), our results suggest that the observed species richness distribution is partly random (the influence of the axis pattern on the data responses was not evaluated here). 


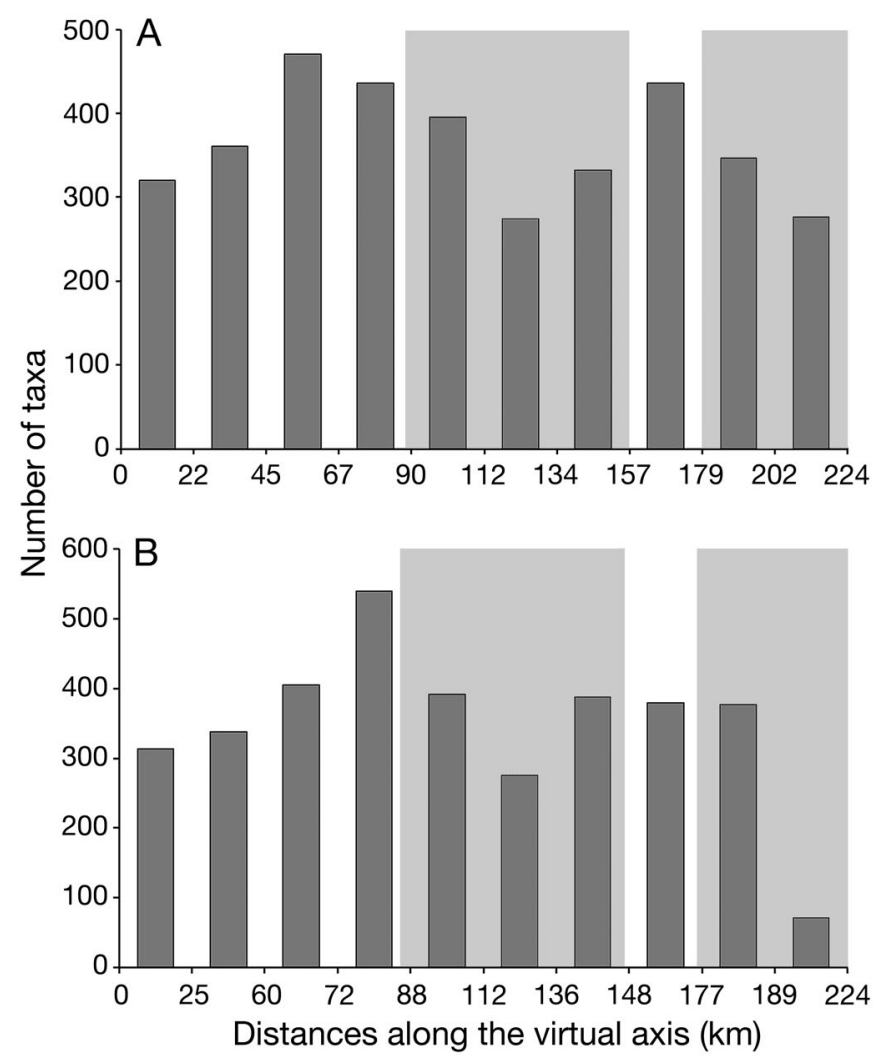

Fig. 7. Number of taxa for (A) fixed number of stations (i.e. constant sampling effort) and (B) equidistant sections along the virtual axis for all data (countable and non-countable taxa; see 'Materials and methods'). Grey areas correspond to the extent of sand sediments

\section{DISCUSSION}

Characterising biological diversity as well as analysing the identity and the role of species in a given ecosystem are important current focuses in ecology. Since the role of a given species in an ecosystem can be variable, certain species may be redundant, thereby ensuring a faster recovery of this ecosystem in the case of disturbance (resilience principle). To better understand these interactions, it is necessary to analyse a stable and diversified ecosystem (Ives \& Carpenter 2007). In the eastern English Channel, a high taxonomic diversity was recorded, with over 860 taxa collected at the 318 stations analysed. Converted to Shannon's index, they correspond to exceptional values (maxima are close to 6 bits) at the scale of the Channel. The taxonomic richness observed in the present study is among the highest in the studies compared here (Table 2). Nevertheless, a quantitative comparison remains difficult because of differences in e.g. scales (local, regional, biogeographical), methodologies (gears, mesh type, sorting) or hetero-

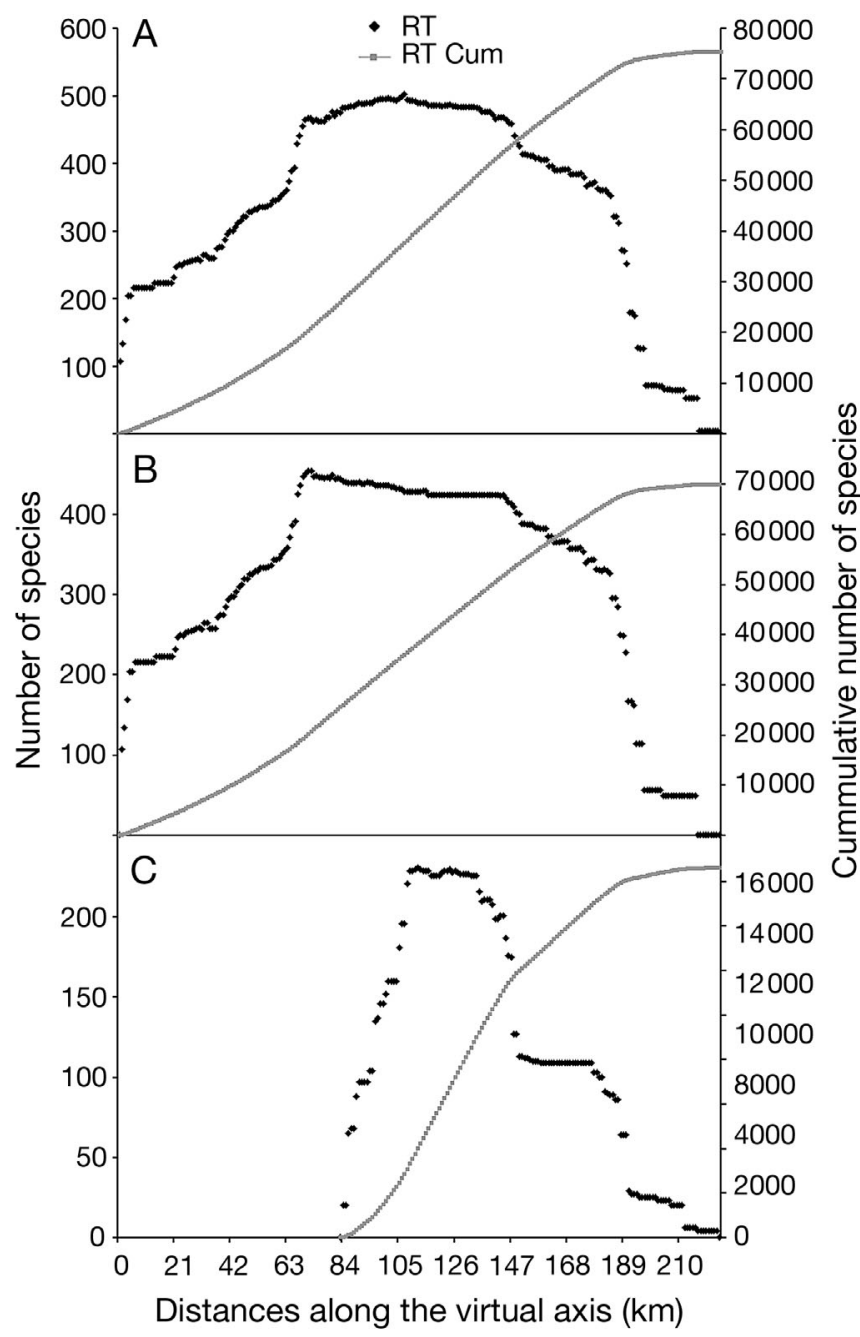

Fig. 8. Evolution of the taxonomic richness along the virtual axis (black) and cumulative number of taxa along the virtual axis (grey) for (A) all stations, (B) gravel/pebble sediments, and (C) sand sediments. RT: taxonomic richness; RT Cum: cumulative taxonomic richness

geneity of habitat. For example, we observed a total taxonomic richness of 875 taxa, which was half that of the Roscoff inventory (1856 taxa; Dauvin \& Dewarumez 2002) representing the diversity of the complex mosaic of habitats of the western English Channel, but was nearly twice as high as the more homogeneous central and southern North Sea (455 taxa). In terms of the relative proportions of phyla in the overall diversity of the area, some phyla were of the same order of magnitude as reported in other studies, such as Mollusca and Echinodermata, with proportions of $\sim 18$ and $\sim 2.5 \%$, respectively. In contrast, phyla such as Annelida, Porifera and the catch-all group 'Others' were completely different depending on the study analysed. Compared to the 


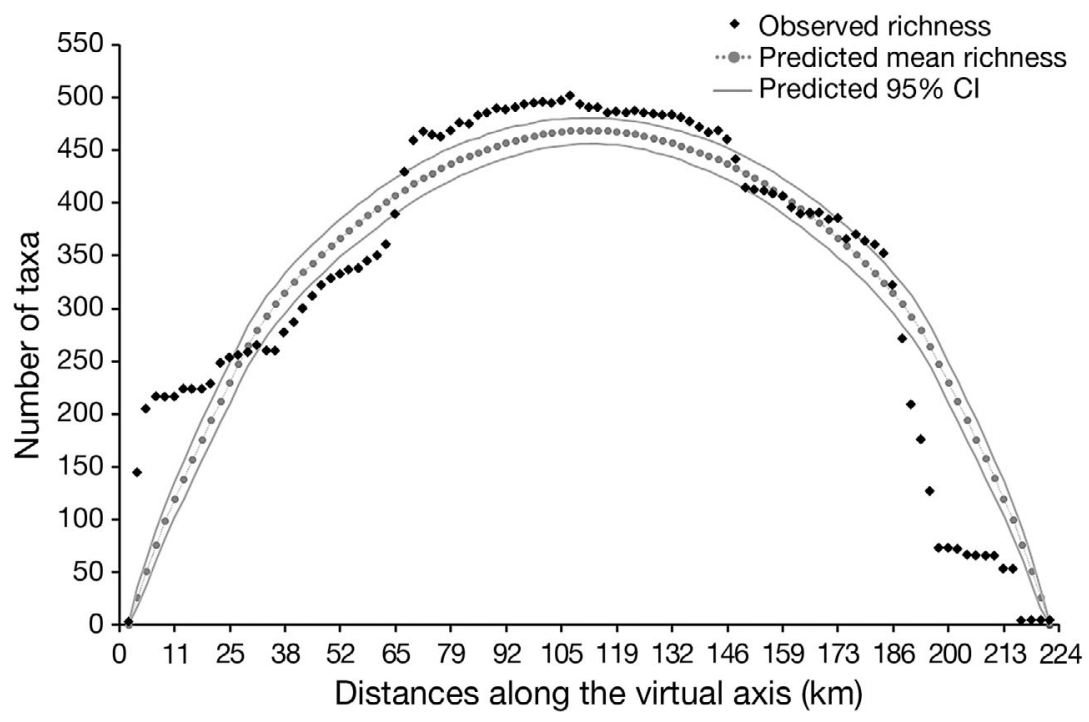

Fig. 9. Observed and predicted taxonomic richness curves for the benthic taxa along the virtual axis in the eastern English Channel. These curves were obtained using RangeModel 5

European dataset (W. Appeltans at European Register of Marine Species pers. comm.), our measures of phyla diversity were similar for Arthropoda, Mollusca, Cnidaria, Echinodermata and Chordata but differed for Annelida (28.9 versus 10.9\%), Bryozoa ( 8.2 versus $3.8 \%)$, Porifera (3.5 versus $7.0 \%$ ) and Others (3.5 versus $16.7 \%$ ) in our study and in the European dataset, respectively.

\section{Difficulties involved in estimations of species richness}

Despite the fact that it may slightly overestimate the richness value, Foggo et al. (2003) considered the Chao1 index to be the best estimator of diversity, and ignored Chao2 and incidence-based coverage estimator indices. In contrast, Walther \& Morand (1998) considered the Chao2 index to be the best, emphasising that almost all of the species richness estimators yielded over-estimations (which is inherent to the sampling methodology). In our case, Chao2 index computation highlighted that, despite a large sampling effort, taxonomic richness remained underestimated. All aforementioned authors agreed that both sampling strategy and scale were the factors that had the greatest influence on the richness estimators. Some studies (Ellingsen 2001, Ellingsen \& Gray 2002) have effectively demonstrated that sampling effort in a determined area must be well thought out. However, in the marine environment, effective sampling is undermined by difficulties in determining boundaries and extents of habitats/assemblages, which often leads to blind sampling (Gray 2000).

The representativeness of the sampling strategy is often a major problem in studies (Gentil \& Dauvin 1988, Ellingsen 2001). An accurate collection of rare species (those known to have low occurrences, i.e. are present at $<5 \%$ of sites, with low probability of collection and variation in pattern distribution) requires a well planned sampling effort. When rare species are 'spot' species (i.e. abundant at 1 site), their distribution patterns are restricted in spatial extent (Colwell \& Coddington 1994, Gray 2000), and a poor sampling strategy would partly miss them, even though they are locally abundant (Ellingsen \& Gray 2002). In our study, the fact that most of the taxa are rare (>500 taxa or $65 \%$ of the total number of taxa) tended to indicate that the sampling strategy was either exhaustive or that these taxa were widely dispersed and thus difficult to collect. Rarity and frequency of collection of a species could also influence the reliability of a species richness estimator. Most of the estimators are sensitive to the number of single species, but also to the spatial structure of a community, which results from the aggregation pattern of each individual species (Foggo et al. 2003).

\section{Sessile epifauna: the main compartment}

Following the recommendation of Colwell \& Coddington (1994), we chose the Chao2 index as our species richness estimator, primarily to integrate the sessile epifauna (which could be considered as aggregated species) in the inventory ( $25 \%$ of the taxonomic richness in the Channel area). Often neglected because of sampling and identification difficulties, this benthic compartment is an important indicator for some marine typologies, such as the EUNIS classification (Connor et al. 2004). This compartment is all the more important because sessile species often provide various microhabitats (see Tsuchiya \& Nishihira 1985 and Kostylev et al. 2005) for other invertebrates, such as the isopod crustacean Anthura gracilis, which is always found in tubes of the polychaete Spirobranchus spp., Terebellidae (polychaete), whose numbers increase with the complexity of 
the 3D structure, or the amphipod Ericthonius punctatus, whose numbers increase with the size of hydroids (A. Foveau pers. obs.). The increase in topographical complexity may increase species richness by creating micro-climate areas, making food resources available and generating refuges and new ecological niches (McCormick 1994, Kostylev et al. 2005). Interstices between heterogeneous/coarse elements also offer enclaves for deposits of fine sediments and the settlement of species that rely on muddy sediments. These microhabitat opportunities could partly explain the differences in specific richness observed between the sand and gravel/pebble sediment categories, as shown by the repartition of the number of species per sediment type in Fig. 3.

\section{Centres of diversity in the English Channel}

Añorve-Sanvicente et al. (1996), who studied the diversity in the eastern English Channel from data collected in the 1970s by Cabioch et al. (1977), highlighted that biological diversity was globally low at the scale of the whole Dover Strait. They did, however, note a diversity hot-spot in the centre of the Dover Strait, which was unusual for the English Channel. This patch, crossing several sediment and community types, was characterised by high species richness with a marked dominance of a few species. The authors thought that this particular pattern of diversity was linked to a large-scale hydrodynamic process, notably the residual transport from the English Channel to the south of the North Sea (Grochowski et al. 1993), which determines larval dispersion, as shown by Dewarumez et al. (1993).

In our study, no clear dominant pattern could be identified (Shannon's diversity index and Pielou's equitability index having high values; see Foveau 2009 for details), and the taxonomic diversity seems highly linked to sediment and benthic community types. High values of species richness were observed on gravel/pebble substrates, located in the western part of the studied area and the Dover Strait. Such differences between historical and recent patterns are difficult to explain since the English Channel is a biogeographical crossing. The longitudinal climatic gradient is a factor determining the distribution of numerous species in the benthic communities (Holme 1966, Cabioch et al. 1977). Depending on their ecological preferences, 2 groups of species may be present (Gentil \& Cabioch 1997): the western species, regrouping (1) oceanic species with a large northward distribution but which also occur in the southern English Channel, and (2) species of warmer climates; the eastern species, also called boreal species, which prefer cold waters and are deterred by the warmer western waters.

Climatic change (e.g. sea temperature increase), inducing species to adapt their distribution patterns (see Mieszkowska et al. 2006), may cause variations in species richness. Areas of high species richness might, then, represent recent increases in the number of species overlaps (ter Hofstede et al. 2010). Climate change may also facilitate the settlement of exotic species or the explosion of some formerly cryptic ones (Burgiel \& Muir 2010, Dewarumez et al. 2011).

\section{Can MDE explain the high diversity in the eastern English Channel?}

Many authors (e.g. Colwell \& Hurtt 1994, Gaston et al. 1998) agreed that in addition to ecological phenomena, geological and evolutionary processes may also influence the distribution of taxonomic richness. In the eastern English Channel, physical and biological parameters contribute to maintaining high biodiversity.

Hydrodynamics are among the most important parameters involved in structuring the species composition in the study region. Indeed, in our study area, strong hydrodynamics associated with low bathymetry causes a mixing of water masses over the whole water column (Agoumi et al. 1983), and coastal and offshore waters have different characteristics (Salomon \& Breton 1991). The central water mass, originating from the Atlantic Ocean, is characterised by low thermal variation, stable marine salinity and low variation of biological and hydrological parameters such as turbidity, nutrient concentrations, phytoplankton composition and abundance (Visser et al. 1996). Conversely, the coastal water mass is characterised by high variation of nearly all physical and biological parameters, essentially in response to the existence of a 'fleuve côtier' (a coastal water flow, directed northward, fed by rivers, in particular the Seine, and characterised by low salinities and high organic matter content), inducing a strong hydrological front whose distance to the coast may shift rapidly according to hydrodynamic and wind regimes (Brylinski et al. 1988). If some communities can withstand such temporal variation of the environment, they may support more species, as suggested by Palmer (1994). Moreover, hydrodynamics have structured the superficial sediment cover. Thus, the eastern English Channel is a mosaic of different 
sediment types (Vaslet et al. 1979). Superficial sediment cover consists of a gradient ranging from coarse sediments (pebbles and gravels) in areas of high tidal energy to fine sediments (sands and muds) in areas of lower energy, such as bays. Finally, the hydrodynamics allow exchanges of larvae coming from the west (western English Channel or Atlantic water masses) or from the North Sea, depending on tidal and wind regimes. The existence of a distribution gradient of species from west to east, as mentioned in some studies (Holme 1966, Cabioch et al. 1977), confirms the openness of the Channel and the possible existence of many species.

The second important element is the heterogeneity of the habitats, particularly in heterogeneous sediments. The fact that elsewhere a variety of microhabitats may be observed in heterogeneous sediments led us to use a fine enough sampling grid to detect, as far as possible, the entire range of taxa. The existence of all of these micro-habitats increased the availability of niches, increasing the possibility of a large number of species, including rarer species, occurring. In this case, competition could be a factor regulating population. However, niche overlap does not necessarily assume competition as long as the conditions of the environment are favourable (Pianka 1974), as might be the case in the eastern English Channel, an area not considered limited in food availability. Moreover, the more species in a community can share resources or use different resources, the richer the community becomes (Pianka 1974, Palmer 1994). However, this particular point cannot be resolved without a serious review of biological species traits and interspecific competition, which is beyond the scope of the present study.

The last important point is the evolution of the communities supported by these habitats. Despite all the niches or food availabilities, communities suffer from natural fluctuations, that are not easily quantifiable. Community evolution could be explained by 'compensatory mechanisms' (Connell et al. 1984), presupposing that, given time, rarer species will tend to increase and commoner ones will decrease, maintaining a sort of equilibrium in the ecosystem. In the eastern English Channel, there is a mix between mature and 'immature' (i.e. non-equilibrium status) communities (rank-frequency diagrams, Foveau 2009, unpublished results), which can explain high values of diversity. These mature and immature communities are created by hydrodynamic factors; life history strategies and resilience of the communities then maintain the equilibrium. May \& MacArthur 1972, Pianka 1974 and Palmer 1994 have shown that in a community, the non-equilibrium status increases species richness because of the existence of high species overlap ('niche overlap hypothesis').

In his review on variation in species richness, Palmer (1994) highlighted the question that has been raised by many ecologists: 'Why do so many species coexist?' He developed the 'competitive exclusion principle' (also known as Gause's law), with 7 associated conditions. For a given 'suite of species, interspecific competition will result in the exclusion of all but one species' (Palmer 1994, p. 519), and the more the conditions associated with this principle are violated, the more species are encountered. In the eastern English Channel, most of the conditions are violated, which can explain the high diversity encountered.

Even though some ecological or biological phenomena may be inferred (Colwell \& Hurtt 1994), random distribution might also explain the observed patterns of species diversity. Random distribution is based on the assumption that for all taxa, all range sizes and placements tend to follow the same distributions between the limits of the studied domain. Random distribution may be related to theories of extinction and minimum viable population size (Lande \& Barrowclough 1987), which state that a large number of individuals is required in a population to ensure its genetic viability, by allowing long-term survival through genetic plasticity and therefore adaptability to environmental changes. The model used in our study emphasises that the spatial variation in range size is linked, in many communities, to the existence of many species restricted to relatively small areas and some species associated with larger areas, the species' geographic range being the fundamental unit. The distribution of taxa with large ranges may affect the geometric constraints of the null model (Colwell \& Hurtt 1994, Colwell et al. 2004). Taxa with small ranges can occur virtually anywhere in a considered domain, in contrast to those with large ranges that are necessarily centred and contained within the domain (since this is a condition of the model). As a consequence, the MDE model seems to be a better predictor of species with large ranges (whose distributions often largely overlap the domain boundary) than of those with small ranges.

The logical continuation of this study, currently underway, concerns the trophic interactions between biological compartments, to better understand the structure of the trophic network (Garcia et al. 2011). Coupling this extraordinary dataset to life-history traits or the role of engineer species should allow us to determine the respective importance of various 
compartments to ecosystem functional diversity and estimate the impact of decreasing marine biodiversity (Gray 2000). This means continuing to collect data in situ and ensuring the highest possible precision in the identification of collected taxa as well as taking into account innovative methods such as habitat modelling. Integrated into management plans of marine ecosystems, such crucial knowledge is strategic for the designation of marine protected areas and associated conservation plans.

Acknowledgements. We thank C. Garcia and everyone involved in the sorting and identification of the species; the officers and crew of the RV 'Côtes de la Manche' for their help at sea; S. Vaz for comments and corrections in English syntax and grammar; and the referees for their helpful suggestions and comments. We also thank R. Colwell for valuable advice with RangeModel and J. Veech for advice about his program script. This work was carried out with various financial contributions, particularly industrial funding (ENERTRAG France, Lafarge Granulats and GIE-GMO), and the European Union's Interreg IIIa and IVa France (Channel) - England cross-border European cooperation programmes (European Regional Development Funds) CHARM 2 and 3 projects coordinated by A. Carpentier, Ifremer, Boulogne-sur-Mer.

\section{LITERATURE CITED}

Agoumi A, Enderlé MJ, Gras RA (1983) Modélisation du régime thermique de la Manche. Oceanol Acta 6: 393-406

> Añorve-Sanvicente L, Leprêtre A, Davoult D (1996) Largescale spatial pattern of the macrobenthic diversity in the eastern English Channel. J Mar Biol Assoc UK 76: 153-160

BEWG (Benthos Ecology Working Group) (1986) Fifth report of the Benthos Ecology Working Group. ICES, Ostende

> Bokma F, Bokma J, Mönkkönen M (2001) Random processes and geographic species richness patterns: Why so few species in the north? Ecography 24:43-49

Brylinski JM, Cabioch L, Conti P, Chabert d'Hières G and others (1988) La notion de 'fleuve côtier' dans les études océanographiques en Manche Orientale. J Res Oceanogr 13:66-67

Burgiel SW, Muir AA (2010) Invasive species, climate change and ecosystem-based adaptation: addressing multiple drivers of global change. Global Invasive Species Programme (GISP), Washington, DC

Cabioch L, Gentil F, Glaçon R, Retière C (1977) Le macrobenthos des fonds meubles de la Manche: distribution générale et écologie. In: Keegan BF, Ceidigh PO, Boaden PJS (eds) 11th Eur Symp Marine Biology. Pergamon Press, Oxford, p 115-128

Chao A (1984) Nonparametric estimation of the number of classes in a population. Scand J Stat 11:265-270

Colwell RK (2006) RangeModel: a Monte Carlo simulation tool for assessing geometric constraints on species richness. Version 5. User's guide and application. Available at: http://viceroy.eeb.uconn.edu/rangemodel

Colwell RK (2008) RangeModel: tools for exploring and assessing geometric constraints on species richness (the mid-domain effect) along transects. Ecography 31:4-7

Colwell RK, Coddington JA (1994) Estimating terrestrial biodiversity through extrapolation. Philos Trans R Soc Lond B Biol Sci 345:101-118

Colwell RK, Hurtt GC (1994) Nonbiological gradients in species richness and a spurious Rapoport effect. Am Nat 144:570-595

Colwell RK, Lees DC (2000) The mid-domain effect: geometric constraints on the geography of species richness. Trends Ecol Evol 15:70-76

- Colwell RK, Rahbek C, Gotelli Nicholas J (2004) The middomain effect and species richness patterns: What have we learned so far? Am Nat 163:E1-E23

Connell JH, Tracey JG, Webb LJ (1984) Compensatory recruitment, growth, and mortality as factors maintaining rain forest tree diversity. Ecol Monogr 54:141-164

Connor DW, James HA, Golding N, Howell KL, Liebernecht LM, Northen KO, Reker JB (2004) The marine habitat classification for Britain and Ireland Version 04.05. JNCC, Peterborough

Dauvin JC, Dewarumez JM (2002) Patrimoine naturel de la Manche orientale et du sud de la mer du Nord. Rev Stn Mar Wimereux 25:9-27

Dewarumez JM, Belgrano A, Craeymeersch JA, Duquesne S, Heip C, Hilde D, Vincx M (1993) Influence de la circulation des masses d'eaux dans la dynamique du peuplement à Abra alba de la baie sud de la Mer du Nord. J Res Oceanogr 18:1-4

Dewarumez JM, Gevaert F, Massé C, Foveau A, Desroy N, Grulois D (2011) Les espèces marines animales et végétales introduites dans le bassin Artois-Picardie. UMR CNRS 8187 LOG et Agence de l'Eau Artois-Picardie, Wimereux

Ellingsen KE (2001) Biodiversity of a continental shelf softsediment macrobenthos community. Mar Ecol Prog Ser 218:1-15

> Ellingsen KE, Gray JS (2002) Spatial patterns of benthic diversity: Is there a latitudinal gradient along the Norwegian continental shelf? J Anim Ecol 71:373-389

Elmqvist T, Folke C, Nyström M, Peterson G, Bengtsson J, Walker B, Jon N (2003) Response diversity, ecosystem change, and resilience. Front Ecol Environ 1:488-494

Foggo A, Attrill MJ, Frost MT, Rowden AA (2003) Estimating marine species richness: an evaluation of six extrapolative techniques. Mar Ecol Prog Ser 248:15-26

Folk RL (1954) The distinction between grain size and mineral composition in sedimentary-rock nomenclature. J Geol 62:344-359

Foveau A (2009) Habitats et communautés benthiques du bassin oriental de la Manche: état des lieux au début du XXIème siècle. $\mathrm{PhD}$ thesis, Université Lille

> Garcia C, Chardy P, Dewarumez JM, Dauvin JC (2011) Assessment of benthic ecosystem functioning through trophic web modelling: the example of the eastern basin of the English Channel and the Southern Bight of the North Sea. PSZN I: Mar Ecol 32:72-86

> Gaston KJ, Blackburn TM, Spicer JI (1998) Rapoport's rule: time for an epitaph? Trends Ecol Evol 13:70-74

Gentil F, Cabioch L (1997) Les biocénoses subtidales macrobenthiques de la Manche, conditions écologiques et structure générale. In: Dauvin JC (ed) Les biocénoses marines et littorales françaises des côtes Atlantique, Manche et Mer du Nord, synthèse, menaces et perspectives, Vol 28. Muséum National d'Histoire Naturelle, 
Paris, p 68-78

Gentil F, Dauvin JC (1988) Peut-on estimer le nombre total d'espèces d'un peuplement macrobenthique? Vie Milieu 38:207-212

Ghertsos K (2002) Structure spatio-temporelle des peuplements macrobenthiques de la Baie de Seine à plusieurs échelles d'observation. PhD thesis, Université des Sciences et Technologies de Lille

Gray JS (2000) The measurement of marine species diversity, with an application to the benthic fauna of the Norwegian continental shelf. J Exp Mar Biol Ecol 250:23-49

Grochowski N, Collins MB, Boxall SR, Salomon JC, Breton M, Lafite R (1993) Sediment transport pathways in the eastern English Channel. Oceanol Acta 16:531-537

Hawkins BA, Diniz-Filho JAF, Weis AE (2005) The middomain effect and diversity gradients: Is there anything to learn? Am Nat 166:E140-E143

Hendriks IE, Duarte CM, Heip CHR (2006) Biodiversity research still grounded. Science 312:1715

> Hewitt JE, Thrush SF, Halliday J, Duffy C (2005) The importance of small-scale habitat structure for maintaining beta diversity. Ecology 86:1619-1626

> Hily C, Le Loc'h F, Grall J, Glémarec M (2008) Soft bottom macrobenthic communities of North Biscay revisited: long-term evolution under fisheries-climate forcing. Estuar Coast Shelf Sci 78:413-425

> Holme NA (1966) The bottom fauna of the English Channel. Part II. J Mar Biol Assoc UK 46:401-493

Ives AR, Carpenter SR (2007) Stability and diversity of ecosystems. Science 317:58-62

Kostylev VE, Erlandsson J, Ming MY, Williams GA (2005) The relative importance of habitat complexity and surface area in assessing biodiversity: fractal application on rocky shores. Ecol Complex 2:272-286

Kröncke I, Reiss H, Eggleton JD, Aldridge J and others (2011) Changes in North Sea macrofauna communities and species distribution between 1986 and 2000. Estuar Coast Shelf Sci 94:1-15

Lande R, Barrowclough GF (1987) Effective population size, genetic variation, and their use in population management. In: Soulé ME (ed) Viable populations for conservation. Cambridge University Press, New York, NY, p 87-123

Larsonneur C, Bouysse P, Auffret JP (1982) The superficial sediments of the English Channel and its western approaches. Sedimentology 29:851-864

May RM, MacArthur RH (1972) Niche overlap as a function of environmental variability. Proc Natl Acad Sci USA 69: 1109-1113

McCormick MI (1994) Comparison of field methods for measuring surface topography and their associations with a tropical reef fish assemblage. Mar Ecol Prog Ser 112: 87-96

Mieszkowska N, Kendall M, Hawkins S, Leaper R, Williamson P, Hardman-Mountford N, Southward A (2006) Changes in the range of some common rocky shore species in Britain - a response to climate change? Hydrobiologia 555:241-251

Palmer MW (1994) Variation in species richness: towards a unification of hypotheses. Folia Geobot Phytotaxon 29:

Editorial responsibility: Romuald Lipcius, Gloucester Point, Virginia, USA
511-530

- Pianka ER (1974) Niche overlap and diffuse competition. Proc Natl Acad Sci USA 71:2141-2145

> Rees HL, Pendle MA, Waldock R, Limpenny DS, Boyd SE (1999) A comparison of benthic biodiversity in the North Sea, English Channel, and Celtic Seas. ICES J Mar Sci 56:228-246

Rees HL, Eggleton JD, Rachor E, Vanden Berghe E (2007) Structure and dynamics of the North Sea benthos. Report No. 288, ICES, Copenhagen

Rex MA, Stuart CT, Hessler RR, Allen JA, Sanders HL, Wilson GDF (1993) Global-scale latitudinal patterns of species diversity in the deep-sea benthos. Nature 365: 636-639

Salomon JC, Breton M (1991) Courants résiduels de marée dans la Manche. Oceanol Acta vol spéc 11:47-53

> Sanders HL (1968) Marine benthic diversity: a comparative study. Am Nat 102:243-282

SHOM (Service Hydrographique et Océanographique de la Marine) (1968) Courants de marée dans la Manche et sur les côtes françaises de l'Atlantique, Vol 550. Imprimerie Nationale, Paris

ter Hofstede R, Hiddink JG, Rijnsdorp AD (2010) Regional warming changes fish species richness in the eastern North Atlantic Ocean. Mar Ecol Prog Ser 414:1-9

Thrush SF, Gray JS, Hewitt JE, Ugland KI (2006) Predicting the effects of habitat homogenization on marine biodiversity. Ecol Appl 16:1636-1642

Tsuchiya M, Nishihira M (1985) Islands of Mytilus as a habitat for small intertidal animals: effect of island size on community structure. Mar Ecol Prog Ser 25:71-81

Vaslet D, Larsonneur C, Auffret JP (1979) Carte des sédiments meubles superficiels de la Manche 1/500 000. Carte géologique de la marge continentale. BRGMIFREMER, Orléans

Veech JA (2000) A null model for detecting nonrandom patterns of species richness along spatial gradients. Ecology 81:1143-1149

Visser M, Batten S, Becker G, Bot P and others (1996) Time series analysis of monthly mean data of temperature, salinity, nutrients, suspended matter, phyto- and zooplankton at eight locations on the northwest European shelf. Ocean Dyn 48:299-323

Walther BA, Morand S (1998) Comparative performance of species richness estimation methods. Parasitology 116: 395-405

Willig MR, Lyons SK (1998) An analytical model of latitudinal gradients of species richness with an empirical test for marsupials and bats in the New World. Oikos 81: 93-98

Willig MR, Kaufman DM, Stevens RD (2003) Latitudinal gradients of biodiversity: pattern, process, scale, and synthesis. Annu Rev Ecol Syst 34:273-309

Worm B, Barbier EB, Beaumont N, Duffy JE and others (2006) Impacts of biodiversity loss on ocean ecosystem services. Science 314:787-790

Zajac R (2008) Challenges in marine, soft-sediment benthoscape ecology. Landsc Ecol 23:7-18

Zapata FA, Gaston KJ, Chown SL (2005) The mid-domain effect revisited. Am Nat 166:E144-E148

Submitted: March 21, 2012; Accepted: October 22, 2012

Proofs received from author(s): March 12, 2013 